This report was prepared as an acoount of work sponsored by an agency of the United States Government. Neither the United States Government nor any agency thereof, nor any of their employees, makes any warranty, express or implied, or assumes any legal liability or responsibility for the aceuracy, completeness, or usefulness of any information, apparatus, product, or process disclosod, or represents that its use would not infringe privately owned rights. Relerence herein to any specific commercial product, process, or service by trade mame, trademart. manufacturer, or otherwise does not necessarily constitute or imply its endorsement, recom* mendation, or favoring by the United States Government or any agency thereof. The views and opinions of authors expressed herein do not necessarily state or rellect those of the United States Government or any agency thereor.

UCRL- -96289

DEB8 00.9971

\title{
Development of the Strong Electromagnet Wiggler
}

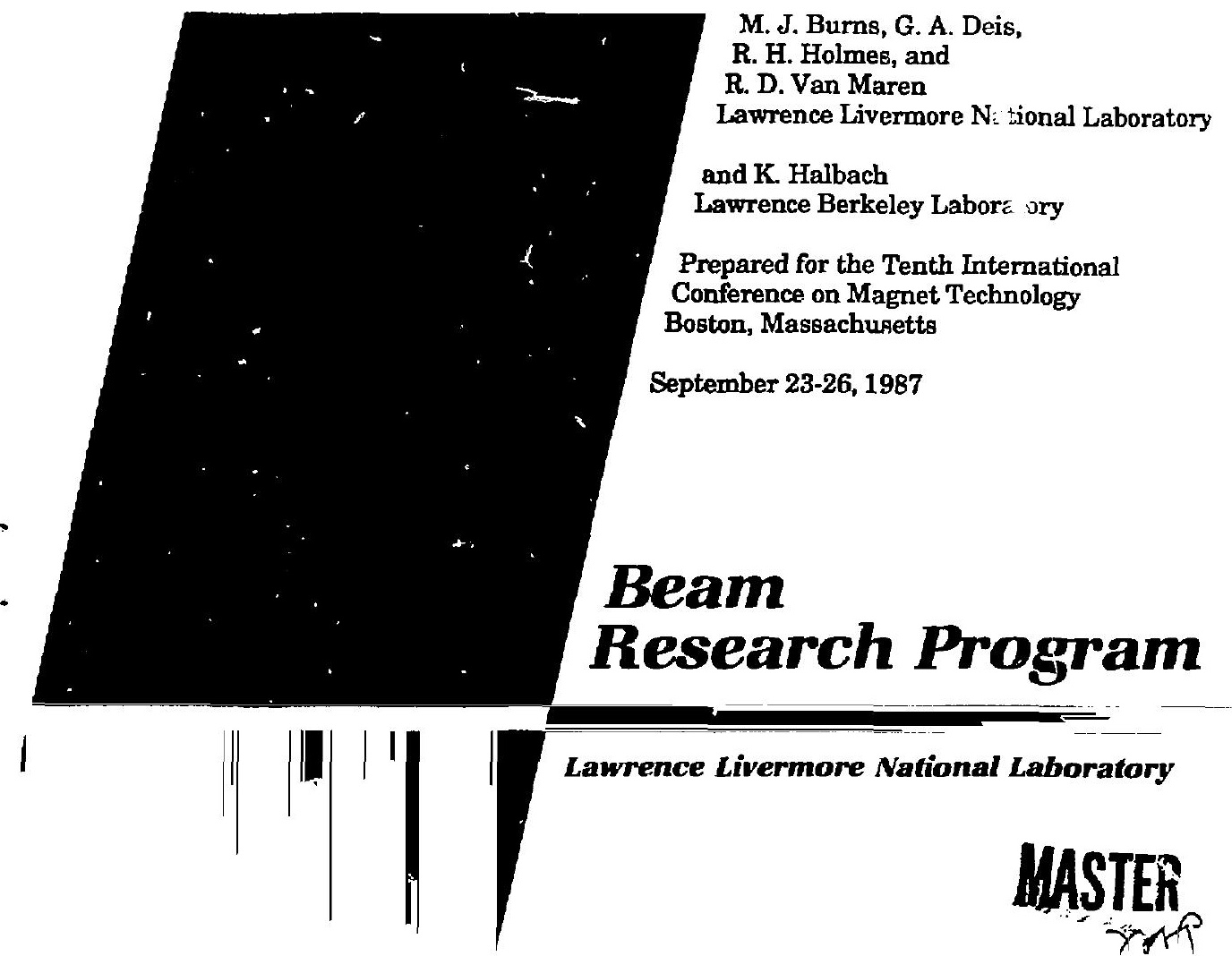


This document was rrepared as an eccount of nork sponsered by an agens of the I nited Stutes Gov ernment. Neither the l'niled Sutes Goiernment nos the liniversity of Californit nor any of their emplosecs. makes any narmanty. expross er implied, n essumes any ketal liability of responsibility for the acraran. compteteness, of mefulens of ans information apparater product. or process disclosed. or represents that its ese would and infrinat privately on ned rights. Reference hereis to any swecific commercial preducts. prosess. or servise by trade mame. tredemart. manufacturer, or ntherw ive, does not necessarily cowstitule or ingh its emdersenent, recominemalioe. or lacoring on ine l'nited Siales Governenent or the leversity of Colifornin. The viens asd capiniens of aubors expressed herein do not becessurily stave or reflect thome of the I aited States Goverament or the Civiersity of Californis, and shatt wot to uned for ediertisine or meduct endorsement perposes. 


\title{
DEVELOPMENT OF THE STRONG ELECTROMAGNET WIGGLER
}

\author{
M.J. Burns, G.A. Deis, R.H. Holmes, and R.D. Van Maren \\ Lawrence Livermore National Laboratory, University of California \\ P.O. Box 808, L-628, Livermore, CA 94550
}

and

\author{
K. Halbach \\ Lawrence Berkeley Laboratory \\ One Cyclotron Road, Berkeley, CA 94720
}

\begin{abstract}
The Strong Electromagnet (5EM) wiggler is a permanent magnet-assisted electromagnet under development at the Law. rence Livermore National loboratory (I.I.NL; as part of the In+ duction Linac Free-Electron-Laser (IFEL) program. This concept uses permanent magnets within the wiggler to provide a reverse bias flux in the iron and thus delay the onset of magnetic saturation. The electromagnet coils determine the uiggler field and operate at low current densities by virtue of their placement away from the midplane. We describe here the design approach used and test data from a 7-period wiggler prototype that includes curved pole tips to provide wiggle-plane focusing
\end{abstract}

\section{Introduction}

The SEM wiggler is a further development of the permanent magnet-assisted electromagnet wiggler, ${ }^{1}$ a type first introduced with the PALADIN wiggler. ${ }^{2}$ It appears that the SEM is likely to rieet the IFEL wiggler requirements of high fielis, large gaps, moderate period length, small random field errors, and field tunability during operation.

The physics of the IFEL system drive these wiggler requirements. To reduce the growth of tine transverse resistive wall instability, which affects high-current electron beams propagated long distances through small pipes with finite wall conductivity, we place the vacuum chamber wall as far as possible from the electron beam. ${ }^{3}$ This requires large pole gaps in the wiggler. Arbitrarily small period lengths prove detrimental to IFEL performance when effects such as finite emittance, beam offset, energy sweep, etc., are considered. Therefore, IFEL wigglers use a moderate period length of several centimeters. Random wiggler field errors cause electron-beam steering and are a particular concern with very long wigglers; thus, we seek designs that can reduce these errors while at the same time providing closed-loop beam steering systems. On-line field tunability is required to optimize the magnetic field taper to any set of potentially varying experimental conditions. Although modeling can predict optimum tapers for the wiggles with a fair degree of accuracy, we must still be able to tune the wiggler around this theoretical profile to allow for changes that might occur on a day-to-day basis throughout the remainder of the IFEL system.

It is the purpose of this paper to describe the single-period design procedure for the SEM wiggler now under development to meet the needs of the IFEL system. We will then discuss a prototype wiggler that demonstrates SEM wiggler performance.

\section{Single-Period SEM Wiggler Design}

The development of new wigglers at LLNL begins with the single-period magnetic design. Once this basic design is understood, we can then address ourselves to system design considerations, which are not included here.
A single-period schematic of the SEM wiggler is shown in Fig. 1. This device, which was first presented by Halbach,' is an iron core, DC electromagnet. Poles of identical magnetic scalar potential are attached to large iron plates. These "scalar potential busses" are bridged by iron plates around which the largt primary coils are wound. A single set of primary coils can control the scalar potential of as many periods as desired. Smaller trim coils that provide the magnetic field taper are placed at the base of the poles. Both sets of coils can have large conductor cross sections and be operated at low current densities by virtue of their placement away from the midplane. Permanent magnet material, magnetized in a direction opposite that of the field created by the coils, is placed between the poles. The permanent magnets provide a "reverse bjas flux" in the iron in the direction opposite that of the coils. Thus, the magnetic scalar potential of tre poles can be elevated to the desired point while delaying the nuset of magnetic saturation in the iron, a fundamental limit to the performance of conventional electromagnetic wigglers.

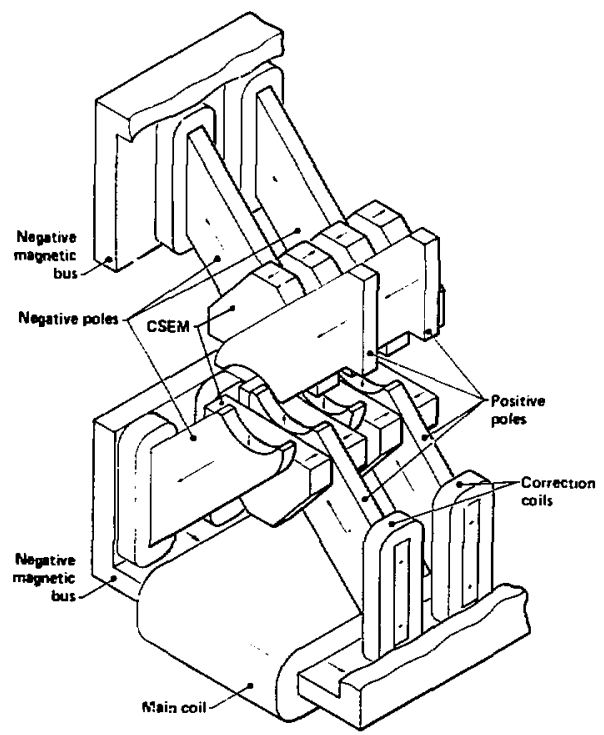

Fig. 1. Single-period schematic of the Strong Electromagnet wiggler. 
While the wiggler is operating away from saturation, permanent magnet flux does not cross the midplane. The operating field. then, is controlled solely by the coils; thus, the SEM functions as an electrosnagnet.

We estimate that the ultimate on-axis field obtainable ', th the SEM is higher than that pussible with a conve.tir:al per. nianent magnet hybrid wiggler of the same geomp:..y and materials. The permanent magnet material next to sie gap in the hybrid wiggler is driven to approximately $0.8 \mathrm{H}_{6}$. Driving the permanent magnet closer to $\mathrm{H}_{\mathrm{c}}$ to obtain higher fields requires a large increase in permanent magnet volume. In the SEM. the coils raise the pole s:alar potential until the permanent magnets are driven fully to $H_{\text {. }}$. For the IFEL. the pole tips are curved greatly in the transverse plane to provide focusing. This reduces the peak field when compared with a flat-pole wiggler.

An interesting characteristic of any permanent magnet-assisted electromiagel is that as coil current is reduced, the large pernnanent magnet flux begins to saturate the iron, thereby placing a luwer limit un the uperation of such a device. In many cases. a significant field remains after the coils are turned off because the saturated iron causes permanent magnet flux to cross the midplane.

The design for the SEM is shown schematically in Fig. 2. The flux in the pole caused by the coils is balanced with an appropriate addition of permanent magnet material magnetized in the opposite direction.

For any given pole shape, the cross-sectional area of the pole limits the allowed net fux. Assuming infinite permeability in the iron, we calculate the distribution of flux caused solely by the coil when the pole is at the scalar potential required to produce the desired midplane field. The SEM design reduces the amount of iron in close proximity to surfaces of oppusite potential so that "parasitic losses"-flux leaving the pole and not crossing the midplane-are also reduced. However, calculation of the flux profile caused by the coils is difficult because of the extremely three-dimensional nature of this configuration.

Permanent magnet material is then placed along the pole as dictated by the profile of the "electromagnetic flux" and the pole cross section. The operating flux profile within the pole is the algebraic sum of permanent magnet and electromagnet flux. At any point along the pole, this resultant must be less than the amount of fux that causes significant saturation.

An important characteristic of the SEM wiggler is the ease with which the pole cross section can be changed. This allows a larger cross section near the base of the pole and can also re-

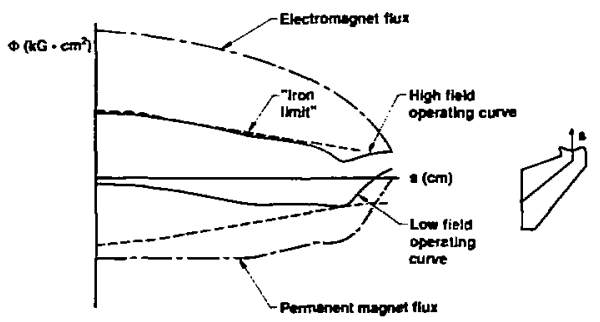

Fig 2. Schematic representation of the SEM design. The electromagnet flax is balanced by the correct location of permanent magnet material and the variation in pole cross-sectional area. duce the total amount of permanent magnet material required. The design process becomes iterative as the desirable pole shape follows from the electromagnet flux profile, which in turns depends upon the shape of the pole.

As seen in Fig. 2. the strength and location of permanent magnet material affects both peak field and tuning range. At the top of the tuning range, the pole begins to saturate near its base, as in a conventional electromagnet. As the ficld is turned down, the unchanging permanent magnet flux causes saturation at the base of the permanent magnet material. These differing "planes of saturation" reduce the tuning range of the SEM when compared to that of a conventional electromagnet

Our definition of tuning range limits wiggler operation beween the prints at which $1 \%$ of the coil ampere-turns (Aturnsl are lost in the iron. This somewhat conservative approach allows the midplane field to be insensitive to incomsistencies in iron properties of a few percent. A-turn loss in the iron is integrited along the entire magnetic circuit, and the long iron paths in the SEM wiggler reyuire us to limit the peak fiedt in C1008 sleel to less than $14 \mathrm{kG}$

Differing pole and coil geometries are possible. The pole configuration (Fig. 3) is especially important. The angled poles intruduce a small field in the transverse plane. Either a dipole or a quadrupole field is generated, and the two possible pole configurations are thus labeled. Note that as the field changes sign in the pole gaps immediately hefore and after a particular pole. so too does the direction in which the poles are attached to the scalar potential busses. Therefore, the sign of the error field does not change.

These small fields can have a significant impact on the uperation of the IFEL. The effect of a dipole error field is obvious; a quadrupole error field detraps particles in the free-electronlaser interaction and significantly reduces laser performance. We are investigating the proper shape of the pole to avoid these error fields. Increasing the vertical extent of the pole tip seems to he effective in this regard.

A single primary coil may be used in place of the two shown in Fig. 1. The top coil plate can be removed, and large iron straps can be placed between the scalar potential busses of like polarity. Although this reduces the power consumption, side access to the pole gap is greatly reduced by the new iron.

Finally; note that the optimization of the SEM wiggler design requires the use of three-dimensional numerical modeling. We have used a series of two-dimensional calculations to arrive at the electromagnet and permanent magnet profiles for certain



"Dipole" configuration

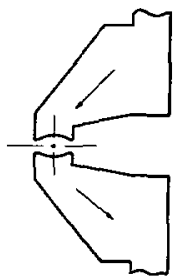

"Quadrupole" configuration
Fig. 3. Schematic showing how pole geometry introduces small error fields. Either quadrupole or dipole fields are produced in the transverse plane caused by the angled poles. Correct shaping of the poles reduces these unwanted fields. 
specific cases. As will be show'n, these calculations have yet to arrive at the optimum design. Computer sinulation is essential because the operating range is the relatively small difference between two large flux components. At LLNL, J.J. Stewart is modifying the three-dimensional finite-element code TOSLA to run more efficiently on either of the LLNL Cray X/MP4 computers. ${ }^{5}$ Additionally. Stewart has dev'eloped a new preprocessor. Wie will use these codes in the final modification of our SEM wiggler prototype. They have also been used elsewhere."

\section{Prototype SEM Wiggler}

We have designed, fabricated, and tested a protutype of the SEM wiggler. Our purpose was to demenstrate the peak field and tuning range possible with our current understanding of the device and in a geometry applicable to the IFEL.

Figure 4 shows the prolotype hardware. The destce has an 8 $\mathrm{cm}$ period and a $3 \mathrm{~cm}$ gap. The center period of the 7 -period niggler is studied to avoid end effects. All iron parts bolt together for easy mudification; thus, the merhanical system is not optmized to reduce random errors. $\mathrm{Sm}_{2} \mathrm{Co}_{1}$ - permanent magnets are used, along with $\mathrm{C} 1008$ steel plate, which was not annealed after machining. The primary coil is constnucted from square, hollow copper conductor, cooled by low-conductivity water.

Figure 5 show's a plot of the midplane field measured on the wiggler centerline v's coil excitation. The peak field observed was $5.8 \mathrm{kG}$, although this point is well beyond the linear portion of the curve and thus does not follow our definition of peak field and tuning range discussed previously Based on the slope of the linear region, peak field determined by a line with a $1 \%$ lower slope is $4.6 \mathrm{kG}$. The minimum field, determined in a


Fig. 4. Photograph of the 7-period SEM wiggler prototype. similar way, is $4.0 \mathrm{kC}$. Extrapolating the linear part of the curve to zero current results in an indicated field of $1 \mathrm{kG}$. We believe that this mav indicate a contribution to the midplane field from the permanent magnets that is caused by saturation within the pole. Further work will address a mudification to the present iron/permanent magnet design to achieve slightly higher fields and a larger tuning range.

Also shown in Fig. 5 is the midplane field measured on the wiggler centerline without permanent magnets installed. The puak field is approximately I $\mathrm{kG}$, which is 22\% of that achieved with permanent magnets.

Note that the curvature of Fig. 5 as the wiggler transitions from low fields ("permanent inagnet saturation") into the linear range of uperation is more pronounced than that seen in the transition to "electromagnet saturation." At higher fields, the base' of the pole begins to saturate, while at lower fields saturation occurs just below the permanent magnets, where the pole cross section is smaller.

Also of interest is the fairiy large amount of hysteresis exhibited. The long iron paths present in the solid iron core result in about $100 \mathrm{G}$ between the upward-and downward-moving portions of the plot.

The correct pole-tip curvature has been dicussed elsewhere, ${ }^{\prime}$ and its shape provides equal horizontal and vertical focusing in the wiggler. We provide the pole-tip curvature by adding iron to the pole as we move away from the wiggler centerline. This reduces the peak field when compared with a flat-tip pole.

Figure 6 is a plot of the normalized transverse field profile on the midplane resulting from the curved pole tips for a centerline wiggler field of $4.5 \mathrm{kG}$. The ideal pole shape would result in a hyperbolic field profile, as indicated. A curve fit to the measured data show's a very close match to the desired field shape. The exact shape of the pole tip deviates slightly from that determined by Scharlemann ${ }^{7}$ to account for the finite width of the pole and to provide for a less costly profiling of the pole.

Also note the slight nonsymmetry of the measured points with respect to the wiggler centerline. This is caused by the error fields associated with the pole geometry.



Fig. 5. On-axis field vs coil excitation. The peak field is as determined by our definition of tuning range, $4.6 \mathrm{kG}$. The tuning range is $600 \mathrm{G}$. Hysteresis caused by the solid iron core is present. The dashed curve represents operation without permanent magnets. 


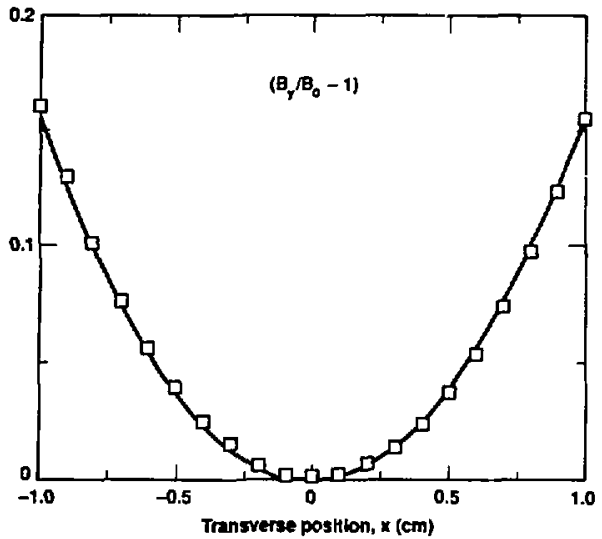

Destied curve:

$\left(B_{y} / B_{0}-1\right)=\cosh \left(\frac{k}{\sqrt{2}} \times\right)-1=0.154 x^{2}$

Curve in to measured dats:

$\left(B_{1} / B_{0}-1\right)=0.157 x^{2}$

Fig. 6. Transverse field profile on the midplane demonstraling the correct field shape for wiggle-plane focusing. Nonsymmetric measured data resull from error fields caused by the pole geometry.

Figure 7 shows an axiai field profile on the midplane along the wiggler centerline, as well as an hannonic analysis of the measurement. The pole thickness along the electron-beam propagation direction is chosen to eliminate the third harmonic on axis. Our pole design was effective in achieving this. In genexal, the field shape exhibits reasonably low harmonic content.

Tests using this prototype device will continue. As it is very flexible, we will investigate new pole shapes to reduce the geometry-induced error fields and increase the peak field and tuning range. We will also use the prototype to begin the study of random-error propagation along an SEM wiggler.

\section{Conclusions}

We have described the Strong Electromagnet wiggler concept and its basic design procedure. This concept is under development to meet the requirements of the IFEL system. We have started testing a 7-period prototype $(8-\mathrm{cm}$ period, $3-\mathrm{cm}$ gap) with curved pole tips. We predicted geometry-induced error fields, then observed them in the measurements. We found that the axial field harmorics were low. Development of the Stong Electromagnet wiggler will contirue.

\section{References}

[1] K. Halbach, "Some concepts to improve the performance of DC electromagnetic wigglers," presented at the Seventh Intemational Conference on Free-Election Lasers, Tahoe City, CA, September 8-13, 1985.

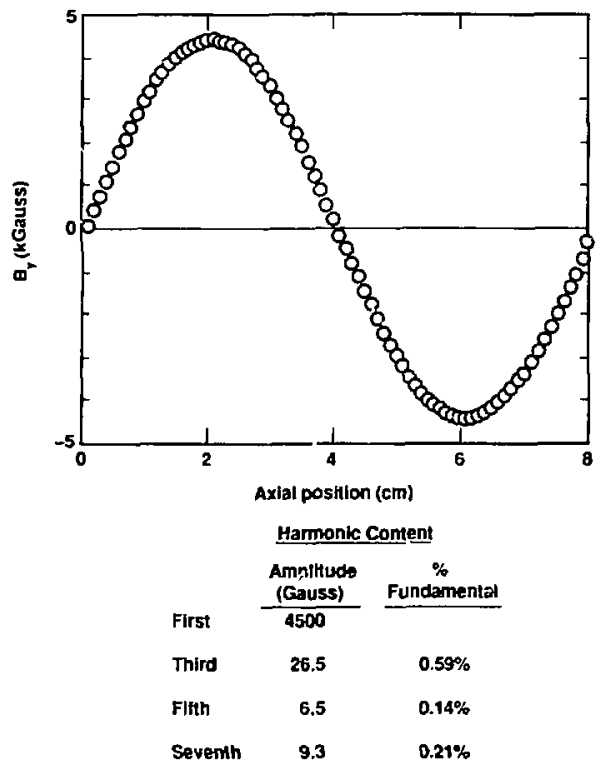

Fig. 7. Axial field profile on the midplane demonstrating low harmonic content.

[2] G.A. Deis, et al., "A Long Electromagnetic Wiggler for the PALADIN Free-Electron Laser Experiments," presented at the Tenth International Conference on Magnet Technology, Boston, MA, September 23-26, 1987.

[3] G. Caporaso, W. Barletta, and V. K. Neil, LLNL. "Transverse Resistive Wall Instability of a Relativistic Electron Beam," Part. Acc., vol. 11, Pp. 71-79, 1980.

[4] H. Shay and T. Scharlemann, "Reducing Sensitivity Errors in FEL Amplifiers," presented at the Ninth Intemational Conference on Free-Electron Lasers, Williamsburg, VA, September 14-18, 1987.

[5] J. J. Stewart, LLNL, private communication.

[6] R.A. Early and J.K. Cobb, "Calculations and Measurements for the SLAC SLC Positron Return Quadrupole Magnet," SLAC-PUB-4093, September 1986.

[7] E.T. Scharleminn, "Wiggler-Plane Focusing in Linear Wigglers," I. Appl. Phys., vol. 58, pp. 2154-2161, September 15. 1985.

Work performed jointly under the auspices of the U.S. Department of Energy by the Lawrence Livermore National Laboratory under W-7405-ENG 48 and for the Department of Defense under SDIO/USA-SDC MIPR No. W31RPD-7-D4041. 